\title{
Notas sobre la historiografía positivista mexicana ${ }^{1}$
}

\author{
Álvaro Matute \\ IIH-UNAM
}

Para Evelia

\author{
Se aclara el contenido del término "positivismo", en \\ relación con los estudios históricos, y se analiza la obra de \\ sus principales exponentes mexicanos.
}

$\mathrm{E}$ xiste mucha confusión acerca de lo que se debe entender por historiografía positivista mexicana. A menudo se aplica la palabra "positivista" a autores y obras mexicanos

1 Este articulo tiene como antecedente "El positivismo, la revolución y la historiografia mexicana", ponencia presentada en el I Coloquio de Análisis Historiográfico, UNAM, agosto de 1978. Por razones que no viene al caso explicar, nunca se publicó, por lo que para hacerlo, lo dí a leer a Evelia Trejo, mi esposa y colega, quien me animó a publicarlo con algunas variantes. Lo mismo opinó José Ortiz Monasterio, quien lo sugirió a Secuencia, que me brinda su hospitalidad. La prueba de fuego me la dieron mis alumnos del doctorado en historia de El Colegiode México: Felipe Ávila, Francisco García González, Leticia Mayer, Pilar Pacheco, Alejandro Pinet Plasencia y Francisco Javier Rodriguez, a quienes agradezco sus comentarios. que no lo son en rigor. El abuso del término ha propiciado la necesidad de tratar de establecer algunos puntos y comas acerca de lo que, en mi concepto, es o debe ser la historiografía positivista mexicana.

A menudo se considera positivistas a historiografias datistas, renuentes a la especulación, sobredocumentadas, etc. En un pequeño manual de introducción a la historia, el autor alemán Paul Kirn afirma que:

Un uso muy extendido del lenguaje designa como positivistas a estudiosos que sólo dan validez a los hechos y rehusan lo más posible el vuelo de altura en el reino de las ideas [...] Este uso del lenguaje debe evi- 
tarse, porque conduce a error. Los padres del positivismo querian ofrecer conocimientos adquiridos con severa crítica y limitarse a ellos; pero se volvieron cada día más unos constructores de dogmas. Su fin fue descubrir las leyes del curso de la historia y organizar la acción de acuerdo con ellas. Para las personas a las cuales se les llama hoy, con abuso del término, positivistas, las leyes de la historia son un horror. Por eso, es mejor reservar la denominación de positivistas para Augusto Comte (1798-1857), los historiadores Hipólito Taine (1828-93) y Enrique Tomás Buckle (1824-62) y a sus partidarios, pues así es como ellos mismos se llamaron. Para los historiadores que desconfian de toda fórmula generalizadora y aun se muestran enemigos de ella, sería más acertada la denominación de nominalistas, ya que vienen a reproducir la misma actitud espiritual adoptada por los filósofos nominalistas de la edad media. Como esta palabra sólo tiene curso en círculos iniciados, preferiríamos la denominación de empiristas. ${ }^{2}$

Con respecto al medio mexicano, William D. Raat propone que el vocablo positivismo sólo sea utilizado para denotar todo aquello que tiene que ver exclusivamente con el pensamiento de Auguisto Comte. A todo lo demás, según este estudioso norteamericano, debe denominársele ciencismo. Pese a que esta proposición ya tiene alrededor de quince años de haber sido pública, no ha tenido mucha aceptación. La sugerencia es infecunda. ${ }^{3}$

Para continuar con las debidas ubicaciones, BenedettoCroce (1866-1952) hace una muy clara distinción acerca de la historiografía posterior al romanticismo, toda aquella que reaccionó contra éste y

\footnotetext{
${ }^{2}$ Kirn, Introducción, 1961, pp. 87-88.

${ }^{3}$ Raat, Positivismo, 1975. El adjetivo "infecundo" le fue dado a la idea de Raat por Roberto Moreno en su excelente obra Polémica, 1984, p. 11.
}

que también a menudo se engloba bajo el único rubro de positivista. Dicha reacción también se levantó, en general, contra la filosofia de la historia y tuvo como protagonistas a historiadores, a filólogos y a filósofos. Los historiadores, dice Croce, elaboraron el lema "la historia debe ser bistoria y no filosofia". No es que negaran la filosofía sino que la deslindaban. La misión de la historia consistía en reproducir lo que verdaderamente ocurrió. Leopold von Ranke (1795-1886) fue el historiador más representativo de esta práctica que el napolitano caracteriza de diplomática por fundamentarse en el documento sometido a las operaciones críticas y heurísticas que pueda ser menester.

Otra de las tendencias que advierte Croce es la de los filólogos que, rechazando toda intromisión del pensamiento en la labor historiográfica, depositaban toda su fe en el texto escrito y se dedicaban a reproducirlo. Esto animó en muchos paises, entre ellos el nuestro, a la elaboración de grandes colecciones de documentos, inéditos y muy raros, que poblaron bibliotecas y facilitaron la consulta de papeles antes inaccesibles a un universo amplio de lectores.

Por fin, los otros que se levantaron contra la filosofía de la historia fueron otros filósofos o acaso también sociólogos, ya que la nueva ciencia antimetafisica se denominó sociología y se basaba en la positividad de los hechos, a partir de los cuales se debían levantar las leyes generales. Croce, al igual que Kirn, recuerda los nombres de Comte, Buckle y Taine. Ellos -y otros como Herbert Spencer (1820-1903)- establecieron que la

verdadera historia se construye con el método naturalista y utiliza la inducción causal; y luego en los múltiples conceptos naturalistas con los que han empapado el 


\section{SECUENCIA}

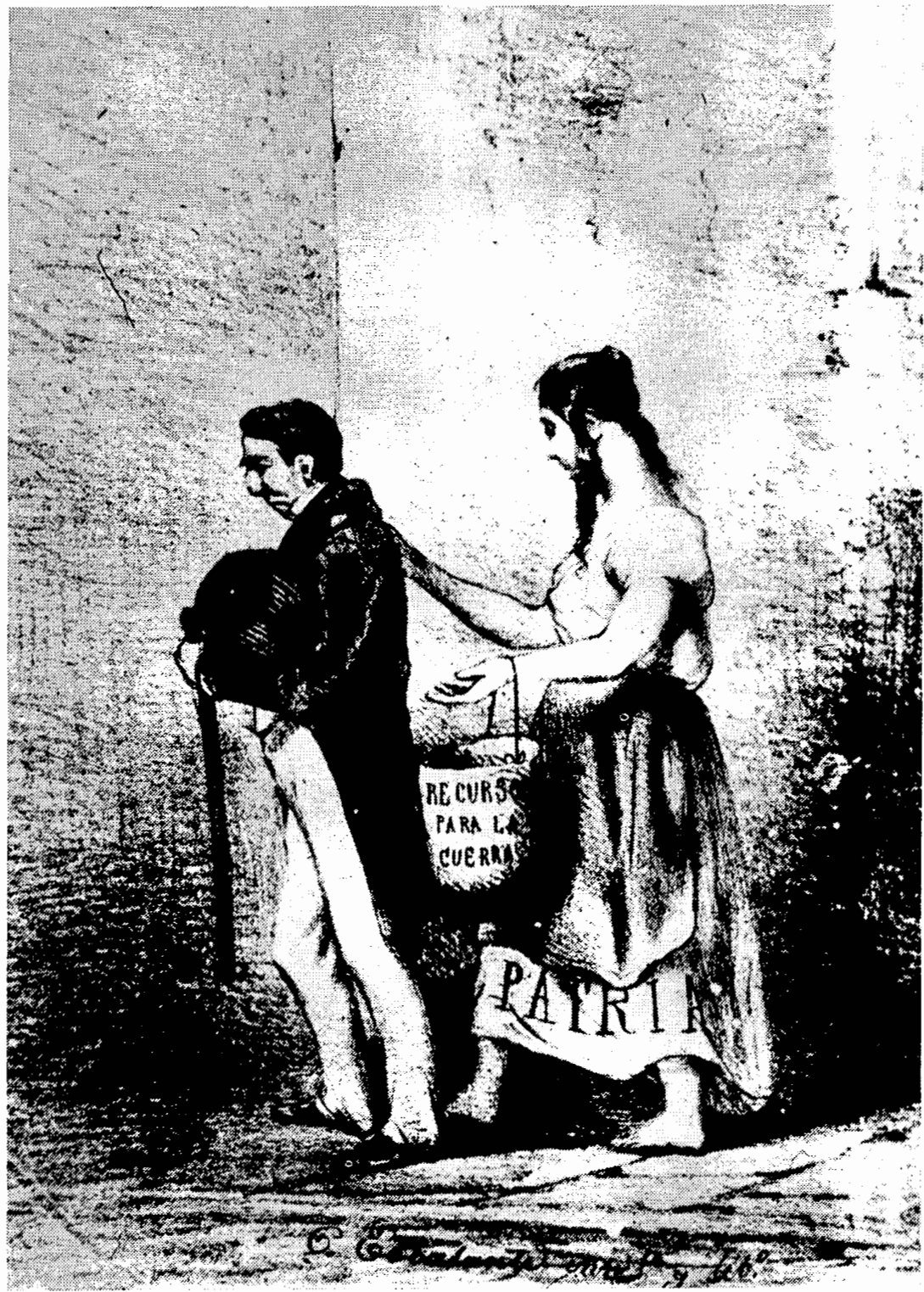


pensamiento moderno: raza, herencia, degeneración, imitación, influjo, clima, factores históricos, etcétera. ${ }^{4}$

Para no extenderme demasiado, puedo concluir provisionalmente, con base en Croce, que tanto en Europa como en América, no toda la historiografía del último tercio del siglo xIX fue positivista, sino que se daba esta triple combinación cuyo fondo común fue su reacción antirromántica y antimetafisica, pero que entre sí desconfiaban unos de otros. ${ }^{5}$

\section{LOS TEÓRICOS POSITIVISTAS MEXICANOS}

No fueron muchos los historiadores que especularon o teorizaron en el medio mexicano acerca de la concepción positivista de la historia, pero afortunadamente algunos no resistieron la tentación. Muchos insertaron párrafos y reflexiones interesantes en distintas obras, en los que hacen profesión de su fe cientificista; entreellos, por ejemplo, Justo Sierra (1848-1912), quien afirmó lo siguiente:

Las ciencias naturales -y la de la sociedad es de ellas, y con la de la sociedad las que hacia ella gravitan, como la historia, la economía política, etc. - resultan cada vez más sobrias en generalizaciones. El periodo juvenil y brillante de las grandes teorías absolutas fundadas sobre un corto número de hechos insuficientemente observados, ha desaparecido, y sólo de vez en cuando algún rezagado adorador de los procedimientos añejos publica su sistema histórico y social, especie de cosmos, sin más valor que el literario; obra de arte, que no de ciencia, en suma. A ese que llamaria-

\footnotetext{
${ }^{4}$ Croce, Teoria, 1955, pp. 233-247. Lo citado, p. 239. Las cursivas son del original.

${ }^{5}$ Así lo caracteriza de manera magistral Croce, Teoria, pp. 239-240.
}

mos el periodo romántico de las ciencias sociales, ha sucedido el realista, si vale decirlo así; el positivo, para darle su nombre legítimo. ${ }^{6}$

Como este ejemplo de Sierra pueden encontrarse otros, acaso menos ilustrativos, pero siempre tendientes a llamar la atención acerca de las bondades de la nueva metodología. ${ }^{7}$

Porfirio Parra (1854-1912) fue quien, de manera a la vez sencilla, breve y sistemática, caracterizó el deber ser de la historiografía positivista en un breve artículo periodístico titulado "Los historiadores.Su enseñanza", ${ }^{8}$ publicadoen 1891. La historiografía debe ser "una verdadera ciencia que pone en relievela relación de causa a efecto, que comprueba la ley de causalidad que asciende de los hechos a la ley, al mismo tiempo que ilustrada por la ley interpreta los hechos".

La historia se divide en dos grandes aspectos, la crítica y la filosofia de la historia: ${ }^{9}$

La primera tendría por objeto establecer los hechos compulsados, los testimonios en que se apoyan, para lo cual habría que aplicar los diversos métodos lógicos que norman la certeza probable. La segunda consistiría en la aplicación severa de la lógica inductiva a la elaboración de los hechos históricos para que de tal elaboración surgiese y se destacase la ley sociológica basada en ellos. ${ }^{10}$

"Sierra, "México", 1948, pp. 131-132.

${ }^{7}$ Para una excelente visión global de la presencia positivista. en la historiografía mexicana, vid González Navarro, Sociologia, 1970.

${ }^{8}$ Reproducido por Ortega y Medina, Polémicas, 1970, pp. 307-309.

${ }^{9}$ Es curioso notar que Parra utilice este concepto y no el de sociología, pese a que ya había pasado lo que González Navarro llama la "sociología enmascarada" que es la manera como Gabino Barreda introdujo el comtismo, sin hacer mención expresa de la palabra "sociologia".

${ }^{10}$ Véase pp. 308-309 del citado artículo. Poste- 
Rescato estas ideas de Parra, expresadas en un texto breve en el cual describe, además, cómo se debía llevar a cabo la enseñanza de la historia a los niños, jóvenes y adultos, de acuerdo con la ley de los tres estadios de Comte.

Por su parte, Francisco Bulnes (1847-1924) también incursionó en terrenos cercanos a la teoría de la historia. Se trata de los dos primeros capítulos de su libro Juárez y las revoluciones de Ayutla $y$ de Reforma (1905) mismos en los que polemiza contra los críticos de su libro antecedente El verdadero Juárez (1904), el cual levantó una enorme reacción que llevó al ingeniero a establecer, entre otras cosas, que él no era historiador sino crítico de la historia y que su misión consistía en corregir lo precedente, para a su vez ser corregido por la posteridad. Para Bulnes, la tarea historiográfica se bifurca en análisis y sintesis, cosas que, asimismo, son funciones de la inteligencia. Las cualidades del análisis son la fineza, la sutileza, la delicadeza, la precisión, la penetración y la profundidad. Todo ello se refiere al tratamiento de los hechos. La primera para "apoderarme del hecho atómico, infinitesimal, celular, molecular", la segunda es la suprema fineza; la delicadeza, por su parte, afecta los procedimientos de observación, de comparación, de clasificación, de método; la precisión consiste en extraer de una masa de hechos el que se necesita, completamente aislado e irreprochablemente verdadero, verificado con pureza de procedimiento. La penetración ayuda a comprender el hecho en todas sus relaciones, su influencia, su importancia para la sintesis, para la generalización. Por

riormente Parra, en su Estudio bistórico-sociológico sobre la reforma en México (1906) publicado como Sociología de la reforma, retoma cuestiones de método, al igual que en su Plan, 1911. último, la profundidad hace avanzar la penetración hasta descubrir los detalles más ocultos. Éstas eran cualidades del análisis. La síntesis, agrega, es la asociación sistemática de los hechos descubiertos, comparados, clasificados por el análisis. Y se permite concluir ese gran sarcástico, que hay dos tipos de sintéticos: los genios y los imbéciles.

El tercer gran expositor de la teoría positivista, a la vez que lúcido crítico del determinismo, fue Ricardo García Granados (1851-1930). "El concepto científico de la historia" es el título de una serie de artículos que publicó en 1910 en la Revista Positiva. ${ }^{11}$ Se trata del ensayo más riguroso aparecido por entonces en los medios nacionales acerca de problemas de teoría de la historia. Llama la atención por su actualización, por el hecho de manejar autores de lenguas inglesa, francesa y alemana que apenas habían publicado sus trabajos, de los cuales tenía no sólo noticia sino una muy clara opinión que expresa con amplituden el texto en cuestión. El leit motiv de García Granados es el determinismo. Revisa todas las teorias deterministas de la historia, desde las providencialistas de tipo trascendente hasta las naturalistas inmanentes, encontrándoles a todas los defectos que las hacian caer, aunque algunas le merecían consideración. Ortega y Medina llama justamente la atención sobre la argumentación del mexicano contra las teorías racistas de Gobineau (1816-1882), inaceptables para todo nativo de países como el nuestro, de raigambre mestiza.

El propio autor resume su trabajo en el párrafo que transcribo:

Hemos pasado revista [...] a las diferentes teorías que se han expuesto para explicar

${ }^{11}$ Recogidos por Ortega y Medina, Polémicas, 1970 , pp. 321-370. 
el desarrollo histórico: la del medio ambiente, la de las razas, la de selección, adaptación y herencia, $y$ en fin la de la fuerza de las ideas. Hemos visto también que aisladamente, todas esas teorias han resultado de lo más defectuosas; peroconsideradas como factores de un conjunto, en sus mutuas relaciones y sus mutuos efectos, adquieren extraordinaria importancia, explicando en gran parte el mecanismo de la psique social, cuyo estudio es el más apropiado para avanzar hacia la solución del dificilísimo problema ante el cual nos hallamos. Ha sido en efecto el punto de vista de la psicología social el que han escogido últimamente para sus investigaciones históricas, algunos de los más notables pensadores.

La formación de la sociedad-agregaexige de cada hombre la renuncia a una parte de sus libertades. Esta autodisciplina es "el rasgo más característico de la psicología social y el que ha determinado en primer término la grandeza o decadencia de las naciones". ${ }^{12}$

Los autores que muestra como ejemplo de esta tendencia a recuperar al individuo dentro de la sociedad, pero sin eliminarla, lo cual implicaría volver al liberalismo de un Carlyle (1795-1881), son Karl Lamprecht (1856-1915), a quien resume y glosa y a quien señala sus puntos comunes con Spencer, aunque a la vez lo distingue de éste al señalar que hay un desarrollo psicológico-social además del orgánico-fisiológico. El otro autor fundamental es el norteamericano Lester F. Ward (1841-1913), quien a su vez distingue entre un desarrollo genético de la civilización, resultado de la acción normal de las leyes naturales, y otro que él llama télico que se efectúa bajo la influencia de la inteligencia. Con base en Ward, García Granados agrega:

${ }^{12}$ lbid, pp. 358-359.
El progreso inferior a lo humano, es totalmente genético en los periodos humanos primitivos, ese progreso es principalmente genético pero comienza a ser télico, hasta que por fin en los tiempos históricos, se convierte ante todo en télico.

García Granados no abandona el positivismo en la medida en que sigue siendo evolucionista, pero supera el esquematismo de Comte y Spencer para distinguir los aspectos materiales, naturales $\mathrm{u}$ orgánicos de los espirituales $\mathrm{O}$ psicológicos, con lo cual introduce o divulga un nuevo elemento dentro del positivismo mexicano. Así, en su esquema evolucionista, la influencia del clima es más evidente en los pueblos primitivos, pero la evolución de los mismos los lleva a liberarse de ella. La historia es una evolución en marcha hacia la libertad. Lo colectivo y lo individual coexisten y no revierte en el otro y viceversa. Su liberalismo lo lleva a argumentar contra los diversos determinismos naturalistas. Pero no debe pensarse que el suyo es un neoliberalismo, sino una búsqueda de equilibrio entre lo social y lo individual.

Con García Granados se cierra el ciclo de coincidencia positivismo-porfiriato, ${ }^{13}$ mas no la producción de teorizaciones históricas positivistas. Los estudiosos defendian posiciones ortodoxas, como don Agustín Aragón (1870-1954) quien refutó la postura idealista de Antonio Caso (1883-1946) alegando que no podía haber sino un solo tipo de ciencia, y la historia no podía ser algo sui generis, como establecía Caso. ${ }^{14}$

${ }^{13}$ Sobre ello, es fundamental el clásico estudio de Zea, Positivismo, 1968. También la antología de Villegas, Positivismo, 1972 y la crítica a Zea en Raat, Positivismo, 1975.

${ }^{14}$ La polémica Caso-Aragón en Ortega y Medina, Polémicas, 1970, pp. 371-423. 
Hacia 1916, don Jesús Galindo y Villa (1867-1937), a propósito de la renovación de los estudios históricos llevada a cabo en el Museo Nacional, asimismo pone al día sus reflexiones sobre la historia. ${ }^{15}$ Por su parte, el oaxaqueño Manuel Brioso y Candiani (1859-1945) refuta a Caso y Aragón por no haber entendido correctamente al rumano Alexandru Dimitriu Xenopol (1847-1920) cuya Teoria de la bistoria fue traducida al castellano por Domingo Baca y alcanzó una difusión notable en México al ser leído por varios autores, como por ejemplo Toribio Esquivel Obregón (1865-1946) quien lo cita en apoyo a lo que debe ser el estudio de la historia. ${ }^{16}$ Pero nadie como Brioso y Candiani, profesor de lógica, despreciado por su sobrino José Vasconcelos, quien le dedica una página en Ulises criollo, de la que el tío no sale bien librado. Lector muy acucioso de Xenopol, publica en su natal Oaxaca un folleto titulado Las nuevas orientaciones para la constitución de la bistoria. ${ }^{17}$ Este texto es una breve exposición de las ideas de Xenopol, bien pensadas y asimiladas por Brioso, quien incluso expresa que el orden que él propone esclarece al rumano. El problema fundamental que quiso atacar Xenopol fue el de la construcción de series de hechos, ya que aceptaba la crítica de los historicistas, en el sentido de que los hechos sonúnicos eirrepetibles y sobre ellos no se pueden establecer leyes. En cambio, se pueden descubrir series de hechos cuya afinidad permita observar regularidades y, a partir de éstas, llegar a la ley. Es tal vez el intento más

1 "Nuevas", núm. 1, pp. 84-93 y núm. 2, 1916, pp. 161-170.

16 "Factors", 1919, pp. 135-172.

${ }^{17}$ El subtítulo reza: Exposición compendiada de la teoria de la Historia de A.D. Xenopol y comentarios por el Lic. $M$. Brioso y Candiani. logrado de restablecer el verdadero espíritu del positivismo.

El último teórico mexicano viene a ser don Andrés Molina Enríquez (1866-1940) con su folleto Clasificación de las ciencias fundamentales. ${ }^{18}$ Más que una teoría de la historia, el breve texto de Molina es un pequeño tratado de epistemología, dentro del cual la historia tiene, desde luego, un papel. La clasificación sigue el espíritu que Comte y Spencer imprimieron a sus sistemas. ${ }^{19}$ Para Molina, que en sus obras de análisis sociológico e histórico siempre dio un papel preponderante a la raza, la historia vendría a ser parte de la étnica, la cual se divide, a su vez, en etnogenia, etnografia y etnología. La etnogenia comprende a la paleontologia, la cronología, la logología (ciencia de la expresión, dividida en gráfica y fonética), la demotopía y la sociología. La etnografía sería lo que se conoce como geografía humana y, por último, la etnología estaría integrada por la arqueología, la historia, la política y la kología o culturología.

\section{INICIOS DE LA HISTORIOGRAFIA POSITIVISTA}

Si bien la primera interpretación de la historia mexicana que utiliza como telón de fondo la ley de los tres estadios de Comte es obra del introductor de la doctrina a México, Gabino Barreda (1818-81), el texto en cuestión no es una obra de carácter historiográfico, sino la famosa Oración cívica del 16 de septiembre de $1867 .{ }^{20}$ La historiografia tardaría en adoptar las enseñanzas de la nueva doctrina. Su primer realizador fue el doctor Fran-

\footnotetext{
${ }^{18}$ Molina Enríquez, Clasificación, 1935.

19 Spencer, Clasificación, 1889, pp. 33-70.

${ }^{20}$ Reproducida en Villegas, Posititismo, 1972, pp. 41-75.
}

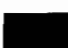


cisco de Asís Flores (1852-1931) en su amplia Historia de la medicina en Méxi$c o$, obra que sigue de manera ortodoxa el esquema de la dinámica social de Comte. Para una historia de la práctica científica, el positivismo resultaba ser una doctrina ideal, ya que la sucesión teología-metafi-. sica-ciencia se amolda a la perfección a la historia de la ciencia, y el doctor Flores lo lleva a cabo de manera ejemplar, dada la acuciosidad con la que investigó la historia médica nacional. ${ }^{21}$

\section{RIVA PALACIO ¿ROMÁNTICO O POSITTVISTA?}

La abundancia de frases tomadas de Charles Darwin (1809-82) y de Herbert Spencer ha llevado a muchos comentaristas a afirmar que Vicente Riva Palacio es un representante típico del positivismo mexicano. No les faltan datos positivos para sostenerlo, y sin embargo, no es del todo exacto. ${ }^{22}$ Y es que Riva Palacio, si bien en edad madura da evidencias de su lectura de los grandes exponentes del evolucionismo, tuvo su formación y su expresión literaria en el romanticismo; dentro de él, como bien ha demostrado José Ortiz Monasterio ${ }^{23}$ fue que Riva Palacio escribió, en compañía de Juan A. Mateos, dos docenas de dramas de contenido histórico, apegado a los cánones de un romanticismo que entró tardíamente a México, pero enraizó y fue coetáneo de los inicios del positivismo. Por razón generacional, Riva Palacio es de

\footnotetext{
${ }^{21}$ Flores, Historia, 1982. La edición original está fechada en 1886, aunque el prólogo de Porfirio Parra está firmado en agosto de 1887 y el Dr. Viesca afirma que el año real de aparición debe ser 1888. Agradezco a Leticia Mayer los datos proporcionados en su trabajo inédito "Progreso", 1991.

${ }^{22}$ Ver, por ejemplo, Parcero, "Liberalismo", 1971, pp. 443-457.

${ }^{23}$ Ortiz Monasterio, Los dramas, 1990.
}

aquellos escritores mexicanos que llegaron tarde al romanticismo, pero se expresaron dentro de él, como Ignacio Manuel Altamirano (1834-93). Cuando su generación llegó a la madurez, el positivismo todavía no era abrazado por los jóvenes, de manera que no les tocó recibir sus principales influencias. No obstante, la inquietud permanente de don Vicente lo llevó a leer a los autores mencionados que le aclararon muchas dudas sobre una de sus obsesiones principales: el mestizaje. Es por ello que se vale con largueza de los evolucionistas para apuntalar sus ideas sobre la formación y el destino de la raza mexicana, producto de la india y la española (ésta, a su vez, muy mezclada), lo que tuvo lugar durante la época colonial. Ciertamente ningún autor de ese tiempo fue insensible a la cuestión del mestizaje, ya que, entre otras cosas, la reforma acabó con el monopolio que los criollos habían detentado del poder. Tocó por vez primera llevar a los mestizos las riendas del poder y estaban demostrando hacerlo mejor que el criollo personificado en Antonio López de Santa Anna. Por otra parte, Riva Palacio era nieto de Vicente Guerrero, otro mestizo destacado en la historia nacional, lo cual lo hacía más consciente de su herencia, que compartía con millones de mexicanos. Pero de ahí a volverlo científico hay un gran paso, que no es claro que haya sido dado por el autor de Martín Garatuza. Se aduce que la concepción de su mayor obra historiográfica, la dirección general de México a través de los siglos y la redacción del volumen II, obedecen a un plan evolucionista. No es imposible que esto sea así, pero también el plan puede deberse al mismo que siguieron tantas grandes historias generales escritas en Europa y Estados Unidos, e inclusive una hecha en España, la de Niceto de Zamacois (1820-85), prime- 
ra obra general sobre México. ${ }^{24}$ Por otra parte, los devaneos evolucionistas de Riva Palacio lo hacen ser sospechoso del positivismo, y en cuanto a los autores de los otros volúmenes, sólo Alfredo Chavero (1841-1906), por su lectura constante de obras antropológicas, podría tener una auténtica base evolucionista, positivista o cientificista, no así Enrique de Olavarría y Ferrari (1844-1918), Juan de Dios Arias (1828-86) o Julio Zárate (1844-1917) y menos que nadie José María Vigil (1829-1909) a quien María de la Luz Parcero califica de "romántico positivista", cuando se trata de términos antinómicos. Vigil fue uno de los combatientes más enérgicos del positivismo, como lo demuestra de manera fehaciente en su $R e$ vista Filosófica. ${ }^{25}$

México a través de los siglos no es una obra positivista. Si bien me rindo ante la evidencia de las múltiples citas de Darwin y Spencer, una lectura cuidadosa de su texto -me refiero a El virreinato-, comparada con el de un típico positivista como Bulnes o Molina Enríquez, arroja una importante diferencia, consistente en que mientras Riva Palacio cita para apoyar sus ideas, los otros además conceptúan, elaboran metáforas y su estructura profunda es absolutamente positivista. En suma, no para eludir una definición, sino para decidir con justeza, Riva Palacio es un caso expreso de eclecticismo intelectual que lejos de menoscabarlo lo engrandece. Su impulso romántico vital trata de llegar a la madurez cientificista en un interesante equilibrio. Si el lenguaje expresa, también disfraza. Lejos de la

${ }^{24}$ Zamacois, Historia, 1876-1882. Un excelente estudio sobre esta obra se debe a Judith de la Torre Rendón, Niceto, 1990.

25 Vid Valverde Téllez, Bibliografía, 1989, vol. II, pp. 151-163. Lo ubica como "impugnador del positivismo", con toda razón. unidad lograda por Bulnes o Molina, Riva Palacio atenúa con su evolucionismo el impulso nacionalista romántico que lo sustenta.

\section{SIERRA: LA PLENITUD EVOLUCIONISTA}

Lo que muchos autores han querido encontrar en Vicente Riva Palacio se da con plenitud en Justo Sierra Méndez. ${ }^{26} \mathrm{Y}$, sin embargo, tampoco está exento del virus romántico, como lo ha mostrado recientemente David Brading ${ }^{27}$ al referir que la primera gran biografia romántica escrita en México se debe a su pluma (y data de una fecha tan tardía como 1906, agrego). No obstante, no hay problema alguno para calificar de representante auténtico y legítimo del positivismo a don Justo. Al igual que Riva Palacio, escribió parte y dirigió una obra de gran envergadura: México: su evolución social. ${ }^{28}$ Su parte, dedicada a la evolución política, es un modelo de asimilación doctrinal en la medida en que no tiene que hacer público ningún repertorio de autores y citas para expresar la asimilación de una idea evolucionista de la historia, de los factores componentes del acontecer y de un conocimiento empírico que lo lleva al verdadero trabajo de síntesis. Su labor personal en esa gran obra colectiva es

\footnotetext{
${ }^{26}$ Entre los comentaristas debo incluir a alguien tan ilustre como don Edmundo O'Gorman, en un par de ensayos muy brillantes: "Tres", 1962 y "Revolución", 1960.

${ }^{27}$ Brading, Mito, 1988, pp. 156-158. Una lectura inteligente de Sierra fue hecha por Garcia González, "Poesía", 1991. Trabajo inédito para mi seminario de El Colegio de México, donde apoyado en metodología novedosa destaca los aspectos románticos y positivistas de don Justo.

${ }^{28}$ Sierra, México, 1900-1902. [Al reverso de la portada también se indica: Barcelona, tipolitografia de Salvat e Hijo, con el año de impresión.]
} 
una de las más logradas de la historiografia mexicana.

Aparte de él, está el repertorio de autores y temas que componen los tres grandes tomos de México: su evolución social. Como sucede en la mayoría de las obras colectivas, no se encuentra en ella ni la unidad metodológica ni la deseada unidad cualitativa. Sin embargo, es un monumento bibliográfico y una obra de importancia historiográfica fundamental. No es este el lugar para intentar una prosopografia de sus autores, aunque ya lo he hecho anteriormente. ${ }^{29} \mathrm{Cabe}$, pues, señalar algunas características sobre ellos. Los hay de la generación de Riva Palacio, es decir, don Manuel Sánchez Mármol (1839-1912) hasta el ingeniero Agustín Aragón, ya mencionado arriba. Es decir, entre el más viejo y el más joven de los colaboradores de Sierra había una diferencia de poco más de 30 años, lo cual se pone en evidencia en su manera de entender la historia que narran y en la de escribirla. Se pasa de un viejo romántico a un joven ortodoxo del comtismo. Y en medio, justamente en el vértice, la generación de Sierra, representada por autores nacidos en los tempranos cincuenta y que, a la vez, estaban insertos en el aparato político porfiriano, cerca de José Ives Limantour (1854-1935), o sea, científicos como los hermanos Miguel (1856-1929) y Pablo Macedo(1851-1918), Gilberto Crespo y Martínez (1852-1916) o Carlos Díaz Dufoo (1861-1941), entre otros. Son ellos, y desde luego Sierra, quienes le dan el tono a la obra. Son ellos quienes hacen gala de su evolucionismo aplicado a México, país que se encuentra en el pináculo de su moderna evolución. La perspectiva de los dos primeros años

\footnotetext{
29 Matute y Trejo, "Historia", 1983. También se ha ocupado de esta obra Flores Hernández, "Letras", 1983, pp. 35-95.
}

del siglo $\mathrm{xx}$ los hace ubicarse en el mejor de los Méxicos posibles. Así lo expresan todos, menos el propio Sierra y Aragón quienes, sin dejar de creer en la evolución que preconizan, afirman que México no está en el pináculo deseado por otros sino que le falta superar serios escollos sociales, según Aragón, y políticos, de acuerdo con Sierra. Volviendo a la totalidad de la obra, pese a trabajos debidos a la pluma del citado Sánchez Mármol, al general Bernardo Reyes (1849-1913), a Ezequiel A. Chávez (1868-1946), es una obra que en su arquitectónica y en la concepción de la historia de sus autores, ejemplifica de manera rotunda el positivismo historiográfico mexicano.

\section{UN SOLITARIO HIPERCRÍTICO: \\ FRANCISCO ALONSO DE BULNES}

Ingeniero, pero sobre todo periodista, polemista, orador de gran efecto, sociólogo e historiador innegable, fue Bulnes, ejemplo de prosa apasionada y científica. La contradicción se resuelve con el hecho de que fue uno de los autores que mayormente se sirvió de la metáfora biológica, química o física para expresar realidades histórico-sociales y explicarlas según los patrones de la sociología vigente, que era una sola ciencia con la historia y que no difería en metodología de las físico-matemáticas. Aunque no abusa del lenguaje como Genaro Raygosa en México: su evolución social, el estilo de Bulnes reúne la virulencia con el cientificismo propio de su formación y de su tiempo. Es bien sabido que Bulnes pasó revista a la historia mexicana, desde la independencia hasta sus días, dejando tan sólo algunos pequeños huecos sin llenar. Todo ello en media docena de libros voluminosos; además es autor de 
un ensayo sociológico en el cual se esclarece su profesión de fe evolucionista y su creencia en la superioridad de unos pueblos sobre otros, debido al tipo de alimentación que los forma. Un repaso de los títulos de sus obras revela su obsesión por la verdad: "Grandes mentiras", "El verdadero" -Juárez o Díaz-, "Toda la verdad...", etc. Bulnes hizo época y levantó ámpula, para saludarlo con un par de esdrújulas. Polemizó con Luis Pérez Verdía (1857-1914) y con Carlos Pereyra (1871-1943). Más de una docena de escritores le censuraron su Juárez. En suma, fue un hombre que no pasó inadvertido y cuya obra se sigue leyendo.

\section{UN CONCURSO SINGULAR}

Con el fin de conmemorar el primer centenario del natalicio de don Benito Juárez, sobre quien Bulnes ocasionó la tormenta que se refirió en el apartado anterior, el gobierno de la república instaló una comisión que organizó un concurso sobre la reforma, dividido en tres ramas: biografia, composición poética y, lo que más interesa, ensayo histórico-sociológico. Como simple dato ilustrativo, mencionaré el hecho de que el periodista veracruzano Rafael de Zayas Enríquez (1848-1932) ganó las dos primeras ramas, con un correcto estudio biográfico y una poesîa de la que prefiero no opinar. La parte relativa al ensayo históricosociológico es la de alto interés para quien estudia la historiografia positivista. El ganador del concurso fue Ricardo García Granados y obtuvieron menciones Porfirio Parra y Andrés Molina Enríquez. Los tres trabajos ${ }^{30}$ tienen en

30 Parra, Sociologia, 1948; García Granados, Constitución 1906; Molina Enríquez, Juárez, 1972. [La primera edición es de 1906]. común no sólo su brevedad sino la apelación a la triada de elementos que Hipólito Taine puso en juego para el mejor entendimiento de una época, a saber, el medio, la raza y el momento histórico. Parra y Molina más que García Granados siguen el esquema del francés. El otro punto es la comprensión de la época de la reforma y la legislación que produjo en función de los factores sociales. Ahí cada uno da matices propios. Frente al equilibrio de Parra está la crítica de García Granados y la insistencia en el mestizaje de Molina. García Granados insiste en la inadecuación de la legislación liberal de 1856-1860 al medio social al que revertía y de ahí los desajustes causados en la actualidad. Por su parte, Parra, de manera más ascéptica, explica la relación entre sociedad y legislación. Molina Enríquez esboza lo que será su gran visión de la sociedad mexicana tres años después, al destacar sus divisiones de grupos raciales a los que asigna una función de clase en la acción social de México. La reforma es obra del mestizo, representado por Juárez. Se trata, en general, de tres textos muy bien logrados que tratan de superar, a través de la historia científica, esto es, positivista, las visiones subjetivas que se presentaron dos años antes, en las que privaba la emotividad y la opinión, frente a la estricta relación entre historia y sociología. Claro está que en los tres trabajos también hay ideología y doxa, pero ellos sentían estar en la ciencia.

\section{EL DERRUMBE DEL RÉGIMEN Y LA HISTORIOGRAFIA POSITIVISTA}

Desde que Leopoldo Zea estudió el positivismo en México, a nadie ha escapado el hecho de su vinculación con el régimen político imperante. La historio- 
grafia, que buscaba la ciencia, destacó por su ideología. Dotó al pasado mexicano de un sentido evolutivo, ya sea continuo, orgánico, en estadios, regido por la supervivencia del más apto, o como sea, pero siempre con la convicción, al revés de fray Luis de León, de que cualquier tiempo pasado no fue mejor.

Francisco Cosmes (1850-1907) en los mismos años en que Sierra emprende su obra monumental, da cima a una suerte de continuación de la voluminosa Historia de México de Niceto de Zamacois. ${ }^{31}$ Cosmes estaba asociado al grupo científico y desarrolla cerca de 4000 páginas cuyo fin es demostrar las bondades del régimen. Mas no todo es loa al presente. También existen señalamientos críticos, con lo que esto que llamamos positivismo no es exclusivamente una filosofia proporfirista; también hay crítica. ${ }^{32}$ En el campo sociológico-historiográfico, la obra más destacada es el clásico Los grandes problemas nacionales (1909) de Andrés Molina Enríquez. Más sociología que historia, pese a ello, hace un excelente uso del pasado para explicar a qué se llegó y a qué se puede llegar. El problema de los problemas radicaba en que no había una evolución lineal, sino que en el presente coexistían grupos socioraciales de diferentes niveles evolutivos, que detentaban distintas formas de posesión o tenencia de la tierra, y eso, en suma, había propiciado el surgimiento de una dictadura mestiza que trataba de unificar la dispersión. La solución a los problemas también debía ser evolutiva.

${ }^{31}$ Zamacois, Historia, 1901-1902.

${ }^{32}$ Esto fue discutido durante la revolución por el médico y filósofo michoacano, de raigambre ortodoxa comtiana, José Torres Orozco, polemizando contra Antonio Caso y José Vasconcelos. Vid, Hernández Luna, José, 1970, así como el prólogo del propio Torres Hernández a Filosofía, 1970.
De la dictadura personal sólo se podía pasar a la de partido y a tratar de establecer un régimen de propiedad titulada de la tierra. En Molina se conjugan pasado y presente de manera magistral. Positivista por cuanto a que sus datos empíricos están sustentados en su experiencia de notario y están entendidos a la luz de la sociología de origen spenceriano, enriquecida por el darwinismo.

Ernest Haeckel (1834-1919) y otras aportaciones. Su libro marca fin y principio de dos épocas. Recoge la experiencia mexicana, de la Reforma a su momento y proyecta lo que puede suceder en el futuro inmediato. Su influencia, pese a la escasa difusión de su libro, fue grande. Se convirtió en un clásico.

En el año crítico de 1910 Emilio Rabasa (1856-1930) culminó una obra fundamental de las ciencias jurídico-políticas, La Constituciónyla dictadura (publicada en 1912). En ella se logra la interdisciplinariedad plena al conjugar los análisis histórico, jurídico, político y sociológico para explicar la realidad. La tónica de sus conclusiones está emparentada con la que expresó en 1906 García Granados, a saber, la inadecuación de la Constitución de 1857 con su medio social. De dicha inadecuación se hace posible la dictadura. ${ }^{33}$ Pero el Rabasa que más interesa aquí es el que en 1920, desde el exilio neoyorkino, escribe su La evolución bistórica de México, verdadero canto del cisne del evolucionismo. Este libro conjuga el talento, finura y penetración del chiapaneco, con su ideologismo, propio de un fiel colaborador del cientificismo porfirista.

$$
{ }^{33} \text { Villegas, "Visión", 1980, pp. 97-125. }
$$




\section{SECUENCIA}

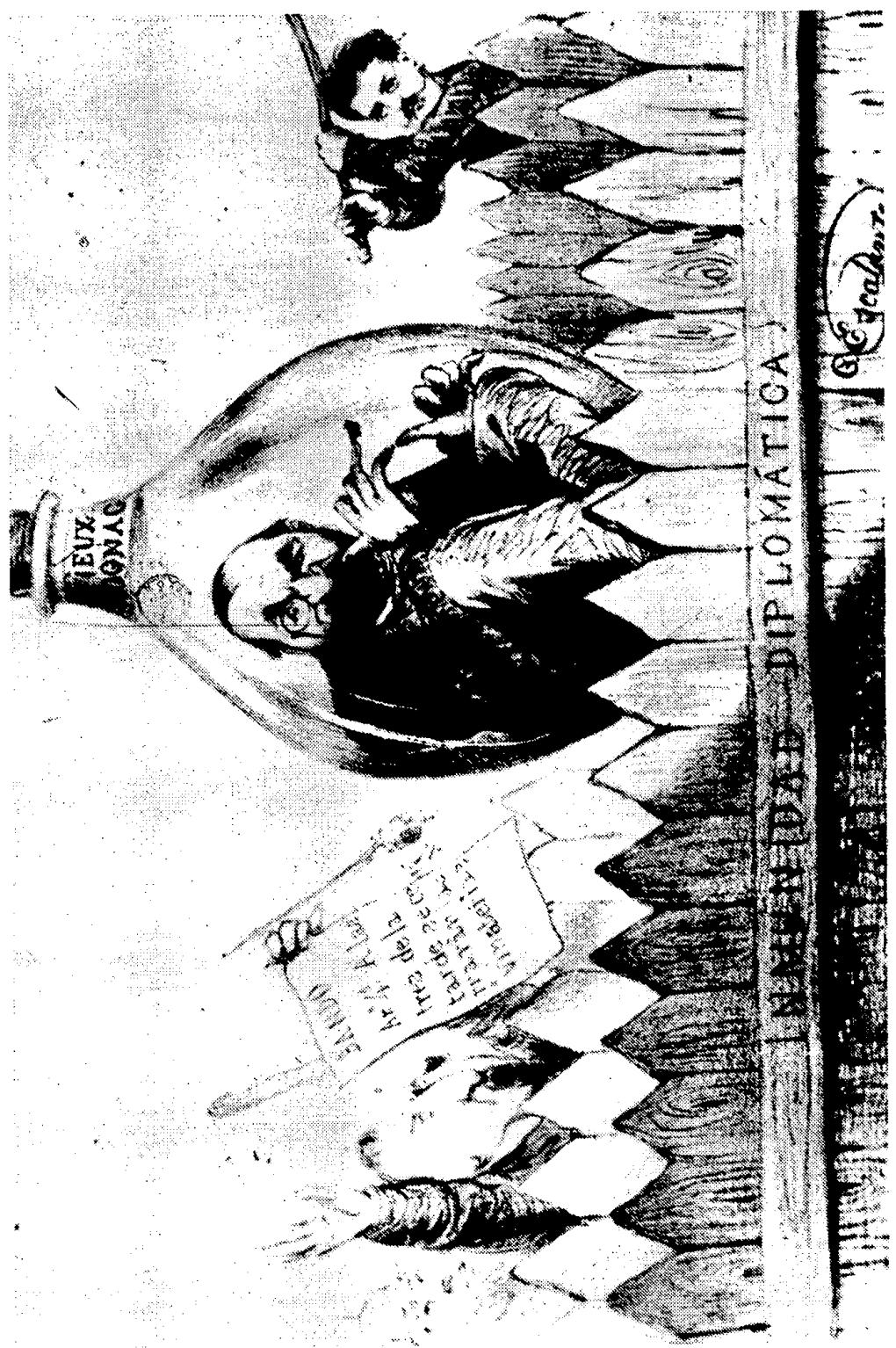


EL PROCESO DE DISOLUCIÓN

DEL POSITIVISMO

La revolución mexicana fue, como dijo José Vasconcelos por entonces, la mejor prueba de la falsedad de la supervivencia del más apto. Las masas subalimentadas, acabaron el orden que sin amor trató de establecer el progreso. Por lo que atañe a la historiografía, también alteró la carrera de la orientación positivista. Es interesante notar cómo algunos de los miembros de la última generación porfiriana, los nacidos a partir de 1865, amanecen positivistas, como corresponde a quien fue educado de acuerdo con la línea oficial, y para demostrarlo escriben sus primeras obras ajustadas a la doctrina. Es el caso de Toribio EsquivelObregón (1865-1946), Victoriano Salado Álvarez (1867-1931) y Carlos Pereyra. Sus obras, publicadas de manera temprana, contienen elementos acusadamente positivistas. En Los episodios nacionales, Salado -de acuerdo con Francisco Jiménez- ${ }^{34}$ establece la filosofia del orden y progreso como una estructura profunda de la trama de lo que ocurre desde Santa Anna a la reforma y durante la intervención y el imperio. Más tarde, en la obra historiográfica de SaladoÁlvarez, el elemento positivista desaparecerá. Lomismo ocurre con las obras de Pereyra publicadas en la primera década del siglo en contraste con sus trabajos posteriores. Esquivel Obregón, por su parte, expresa ideas evolucionistas y reconocimiento a Xenopol y Altamira y Crevea (1866-1952) en 1919, para en obras posteriores abandonarlo y producir una historiografia desociologizada, cubierta por la ideología del conservadurismo histórico mexicano de raigambre hispanista.

${ }^{34}$ Jiménez, Episodios, 1974. Especialmente los capítulos II y III donde trata la visión de la historia de Salado y la educación positivista.
Pero en términos generales, lo que les sucede a los tres historiadores arriba mencionados es sólo una muestra de una situación más amplia. La revolución permite que afloren dos tendencias historiográficas contrapuestas, que tienen en común la ausencia de orientación doctrinaria, es decir, carecen de la guía positivista propia de la más característica producción histórica porfiriana. En 1974 caractericé a estas tendencias con los nombres de tradicionalismo empírico y pragmatismo político. ${ }^{35} \mathrm{La}$ primera es una reacción contra el presente, en la medida en que éste amenaza con destruir las herencias históricas mexicanas. Es una actitud restauracionista que fundamentalmente se cifra en el pasado colonial, al que rescata y enaltece, así como a la práctica obsesiva por publicar documentos inéditos y muy raros. Por una parte destacan autores como don Luis González Obregón (1865-1938) y por la otra don Genaro García (1867-1920). Si bien alguien puede caracterizarlos, sobre todo al segundo, de positivistas ${ }^{36}$ por el hecho de publicar documentos, ya he explicado por qué esta práctica por sí sola no es positivista.

La tendencia contrapuesta, el pragmatismo político, es aquella que desde el presente aprovecha el pasado inmediato para hacer historia de lo que está pasando o acaba de ocurrir. Es la historiografia que surge de la caída del régimen de Díaz, y que escribirán todos los participantes en la revolución que tomaron la pluma para justificar, explicar o simplemente recordar lo que hicieron. Ni aquéllos niéstos necesitaban apoyo filosófico. El empirismo bastaba para apelar a un

${ }^{35}$ Matute, Teoria, 1974.

${ }^{36}$ Cfr. Vázquez Mantecón, "Genaro", 1983. Se trata del facsímil del tomo $\mathrm{xxx}$ de la Colección de documentos inéditos y muy ranos que dirigió don Genaro de 1904 a 1914. 
pasado lejano en una especie de actitud neoromántica o para discutir a favor o en contra de la revolución entonces actuante. Spencer, Comte, Mill, Taine, Buckle, Haecke, Darwin y otras autoridades de la historiografía surgida a finales del siglo XIX habían sido olvidados. Sus ideas ya no eran llamadas para apelar a establecer los diagnósticos sobre la realidad presente o pretérita. Quedaba, sí, la herencia metódica: el tener que basarse en los datos positivos, empíricos, para construir con ellos las narraciones de lo que realmente pasó sin sustentarlas en creencias metahistóricas.

\section{BIBLIOGRAFIA}

-Brading, David, Mito y profecia en la bistoriade México, Editorial Vuelta, México, 1988.

-Brioso y Candiani, Manuel, Las nuevas orientaciones para la constitución de la bistoria, Talleres de Imprenta y Encuadernación del Gobierno del Estado, Oaxaca, 1927.

-Croce, Benedetto, Teoria e bistoria de la bistoriografia, traducción de Eduardo J. Prieto, Editorial Escuela, Buenos Aires, 1955.

-Esquivel Obregón, Toribio, "Factors in the historical evolution of Mexico", Hispanic American Historical Review, vol. II, núm. 2, mayo de 1919, pp. 135-172.

-Flores Hernández, Benjamín, "Las letras y las armas en México: su evolución social", Estudios de bistoria moderna y contemporánea de México, vol. $\mathrm{x}, 1983$, pp. 35-95.

-Flores, Francisco de Asis, Historia de la medicina en México, estudio preliminar de Carlos Viesca Treviño, 3 vols., Instituto Mexicano del Seguro Social, México, 1982.

-Galindo y Villa, Jesús, "Las nuevas directrices en los estudios históricos", Gladios, año 1, núm. 1, enero de 1916, pp. 84-85 y núm. 2, febrero de 1916, pp. 161-170.

-García González, Francisco, "La poesía en la historia de Justo Sierra" (inédito).

- García Granados, Ricardo, La Constitución de 1857 y las Leyes de Reforma, Tipografia Económica, México, 1906.
-González Navarro, Moisés, Sociología e bistoria en México, El Colegio de México, México, 1970 (Jornadas, 87).

-Hernández Luna, Juan, José Torres Orozco. El último positivista mexicano, México, 1970.

-Jiménez, Francisco, Los episodios nacionales de Victoriano Salado Álvarez, Editorial Diana, México, 1974.

-Kirn, Paul, Introducción a la ciencia de la bistoria, traducción de Orencio Muñoz, UTEHA, México, 1961.

-Matute, Álvaro, La teoría de la bistoria en México (1940-1973), SEP, México, 1974 (Sepsetentas).

y Evelia Trejo, "La historia antigua en México: su evolución social", ponencia presentada en el VI Coloquio de Análisis Historiográfico, México, 28-30 de marzo de 1983.

-Mayer, Leticia, "Progreso, ciencia y nacionalismo" (inédito).

-Molina Enríquez, Andrés, Clasificación de las ciencias fundamentales, Museo Nacional de Arqueología, Historia y Etnografia, México, 1935, 2a. ed.

, Juárez y la reforma, B. Costa Amic, México, 1972, 5a. ed.

-Moreno, Roberto, La polémica del darwinismoen México, sigloXIX. Testimonios, UNAMIIH, México, 1984.

-O'Gorman, Edmundo, "La revolución mexicana y la historiografia", Seis estudios bistóricos de tema mexicano, Universidad Veracruzana, Xalapa, 1960, pp. 207-220.

"Tres etapas de la historiografía mexicana", en Anuario de bistoria, año II, 1962, pp. 11-19.

-Ortega y Medina, Juan, Polémicas y ensayos mexicanos en torno a la historia, UNAMIIH, México, 1970.

-Ortiz Monasterio, José, "Los dramas y las novelas históricas de Vicente Riva Palacio", tesis de licenciatura, UNAM-FFyL, México, 1990. 2 vols.

-Parcero, María de la Luz, "El liberalismo triunfante y el surgimiento de la historia nacional", Investigaciones contemporáneas sobre la bistoria de México. Memorias de la Tercera Reunión de Historiadores Mexicanos

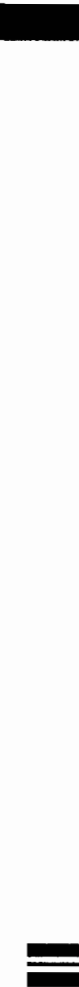


y Norteamericanos. Oaxtepec, Morelos, 4-7 de noviembre de 1969, UNAM/El Colegio de México/The University of Texas, Austin, México, 1971, pp. 443-457.

-Parra, Porfirio, Plan de una bistoria general de Chibuabua oindice razonado de los capitulos que deberánformarla, Tipografia de la Viuda de F. Díaz de León, México, 1911. Sociología de la reforma, Empresas Editoriales, S.A., México, 1948 (El liberalismo mexicano en pensamiento y acción, 8).

-Raat, William D., El positivismo durante el porfiriato, traducción de Andrés Lira, SEP, México, 1975 (Sepsetentas, 228).

-Sierra, Justo, México su evolución social. Sintesis de la bistoria política, de la onganización administrativa y militar y del estado ecomómico delafederación mexicana: desuadelantamiento en el orden intelectual; desu estructura territorial $y$ del desarrollo desupoblación, y de los medios de comunicación nacionales e internacionales; de sus conquistas en el campo industrial, agricola, minero, mercantil, etc., etc. Inventario monumental que resume en trabajos magistrales los grandes progresos de la nación en el siglo XIX, J. Ballescá y Compañía Sucesor, México, 1900-1902, 3 vols. "México social y político. Apuntes para un libro", en Obras completas del maestro Justo Sierra, $X$. Ensayos y textos elementales de bistoria, edición ordenada y anotada por Agustín Yánez, UNAM, México, 1948.

-Spencer, Herbert, Clasificación de las ciencias, Biblioteca Económica Filosófica, Madrid, 1889.

-Torre Rendón, Judith de la, "Niceto de Zamacois y la búsqueda de la reconciliación de la sociedad mexicana", tesis de licenciatura, ENEP-Acatlán, México, 1990.

-Torres Orozco, José, Filosofia, psicologia $y$ ciencia, edición de Juan Hernández Luna, México, 1970(Colección Un gran michoacano. Su vida, su pensamiento, su acción).

-Valverde Téllez, Emeterio, Bibliografía filosófica mexicana, estudio introductorio de Herón Pérez Martinez e indices elaborados por Pilar González y Marcelo Sada, El Colegio de Michoacán, Zamora, 1989, 2 vols. (edición facsimilar).

-Vázquez Mantecón, Carmen, prólogo a "Genaro García y la historia positivista", en Antonio López de Santa Anna, La guerra de Texas, uam, México, 1983 (Colección de Cultura Universitaria. Serie Testimonios).

-Villegas, Abelardo, Positivismo y porfirismo, Secretaría de Educación Pública, México, 1972 (Sepsetentas, 40).

-Villegas, Gloria, "La visión histórica de Emilio Rabasa", Estudios de bistoria moderna y contemporánea de México, 1980, vol. vIII, pp. 97-125.

-Zamacois, Niceto, Historia de México, desde sus tiempos más remotos hasta nuestros días, J. F. Parrés y Compañia, BarcelonaMéxico, 1876-1882, 20 vols.

-Zea, Leopoldo, El positivismo en México. Nacimiento, apogeo y decadencia, FCE, México, 1968. 